was 5 per cent. (2) Diseases due to abnormality of internal secretion, such as diabetes, pernicious anæmia, Addison's disease, myxoedema, cretinism and simple goitre, tetany and osteitis fibrosa cystica. As an example, reference was made to the latest results obtained in the treatment of pernicious anæmia by the pure or nearly pure anti-anæmic principle of liver as recently isolated by Dakin and West. So little as $0.2 \mathrm{gm}$. injected once weekly has a remarkable curative effect on this otherwise deadly disease. (3) Nutritional disease: Dr. Mellanby illustrated this subject by showing how discoveries leading to the cause, prevention and cure of rickets had been obtained. He also dealt with the problem of defective teeth and said that dental decay will remain a scourge in Great Britain unless methods are adopted of feeding infants and children on diets which would produce perfectly formed instead of the present imperfectly formed teeth. He described the beneficial effect of such substances as abundant milk, egg-yolk, fish and animal fats on dental structure, as compared with the harmful effect of cereals such as oatmeal, flour and other similar substances unless balanced by sufficient milk.

\section{The Case Against Vaccination}

Is his Chadwick Public Lecture delivered at the Royal Society of Tropical Medicine and Hygiene, on November 1, Dr. C. Killick Millard discussed the vaccination question. In the past, one either had to believe in vaccination or to disbelieve in it. Dr. Millard said that his faith in vaccination, as a means for protecting the individual against smallpox, is just as strong and unassailable as ever it was, but he recognises that, as a State institution for protecting the community, infant vaccination has been largely a failure. Until recently, it was taught that the neglect of infant vaccination entailed serious and imminent risk of a return of smallpox mortality. The experience of the City of Leicester, which abandoned infant vaccination fifty years ago, and yet where, during the last thirty years, there have been only two deaths from smallpox, makes such a belief difficult. Since the War, an ultra-mild form of smallpox has appeared in Great Britain and considerable spread has taken place. It has now been officially recognised as a distinct variety, which breeds true, and it has been accorded a separate name, 'variola minor', to distinguish it from the severe form of smallpox, 'variola major'. As a matter of fact, although not officially recognised as such, variola minor existed in Great Britain long before the War, and in certain countries, under the name of 'alastrim', it has existed from time immemorial. Variola minor presents quite a different administrative problem from variola major. Compared with the latter it is non-fatal, non-disfiguring, non-loathsome. In some ways it is no more serious than vaccination, so that no case can be made out for retaining compulsory vaccination merely on account of variola minor. Dr. Millard concluded by expressing the opinion that the repeal of the vaccination Acts is now over-due.

\section{Liberation of the Electron}

For his Friday evening discourse at the Royal Institution on November 1, Mr. C. C. Paterson took as his subject "The Liberation of the Electron". He described how the whole art of electrical engineering had been born again when the electricity, which the older engineers had confined to wires and cables, was liberated from them by the physicist and handed back to the engineer to be exploited in the wireless valve, the photo-electric cell, the cathode ray tube, and other devices which use 'free electrons'. He demonstrated the essential causes which enabled these devices to establish broadcasting, long-distance telephony, television, and similar social services. The secret of the revolution is that a stream of free electrons, whether in a vacuum or a gas, can be manipulated with such facility that the electricity can be increased or decreased at the rate of millions of times per second, or alternatively as slowly as desired, and no limit is set to the amount of energy which can be so controlled. So much of what we see and hear consists, if analysed, of extremely rapid happenings. The eye and the ear are unconscious of these high-speed fluctuations and vibrations, although sensitive to them. In order that we may faithfully reproduce and transmit these very rapid oscillations and variations, it is necessary to make exact electrical copies of them. This is done by suitably controlling a stream of free electrons. Mr. Paterson went on to point out how the free electron is also being used in astounding ways in the art of electric lighting. The many coloured luminous discharge tubes used for display purposes in the streets are due to the action of 'free electrons'. They have led the way to more brilliant and more efficient industrial light sources. Some of them give much more light for the electricity consumed than existing filament lamps. The effects are the result of high-speed (up to six million miles an hour) encounters between free electrons and the gas atoms in the tubes.

\section{Science and Unemployment}

IN his presidential address to the Institution of Electrical Engineers delivered on October 24, $\mathrm{Mr}$. J. M. Kennedy dealt mainly with the subject of the distribution of electricity. It is obvious that hand labour is gradually being replaced by mechanical power, and that a large fraction of the labour so displaced is unable to find further employment. There are certain depressed areas in which unemployment is particularly rife owing to the dying out of industries or their transfer to more suitable areas. It is now generally recognised that lack of forethought and absence of planning for the future during the recent rapid industrial development has been one of the main factors that has allowed these industrial troubles to develop. Absence of initiative and the policy of letting things drift often prevent real progress from being made. Mr. Kennedy discussed the relation between advancing applications of science and unemployment. He does not agree with those who fear that any steps taken to plan industry so as to re-absorb the present number of unemployed 
will cause difficulty in the event of a great revival of trade. So far as the electrical industry is concerned, those employed in manufacturing, contracting and supply have grown in number from 200,000 to 330,000 in the last ten years. Scientific and technical development soon find a remedy for any potential shortage of work by increasing the rate at which power is developed and utilised. He reminded his hearers that electricity is a commodity in everyday use, and that it is unnecessary to fill up complex forms before it can be supplied. If the present rate of progress is to be maintained, more intensive effort and in many cases an appreciable reduction of tariffs is required.

\section{School Dietaries}

THRovgh the laxity of their parents in nutritional matters, nearly all children go to boarding schools as 'damaged goods'. This accusation, which is broadly true, is made by Prof. H. E. Armstrong in No. 7 of the gastronomical quarterly Wine and Food, in which he reviews Dr. Friend's book "The Schoolboy. A Study of his Nutrition, Physical Development and Health". Schools may not be able to repair the injury inflicted by parental carelessness, but at least they should not add to it, as they commonly do, by providing ill-planned dietaries during the crucial period of adolescence. For more than twenty years resident medical officer at Christ's Hospital, Dr. Friend has striven to better the physical condition of the boys passing under his care by improving the biological quality of the school diet. These experiments have been watched and encouraged by Prof. Armstrong in his capacity as a governor of the school. Prof. Armstrong is constantly directing his stinging wit and pungent criticisms at first one and then another public nuisance. The problem with which he is exercised at the moment is :

$$
\begin{aligned}
& \text { "How should the little busy boy } \\
& \text { His belly daily fill ?" }
\end{aligned}
$$

Prof. Armstrong urges the introduction of wholemeal bread; far more vegetables, particularly in a raw state; a comprehensive sausage including some of every kind of 'innards' ; milk and milk products, of course. For the better provision of bone-forming minerals and vitamins, the milk should be from herds on lime-treated pastures, and in winter-time the cows should be fed on hay made from rapidly dried young grass.

THE large boarding school of the future will call for the exercise of special activities and of special intelligence on the part of the staff. The training of the child's character will be through that most wonderful House of Assembly, the 'tummy', and not through the pursuit of cricket and foot balls and dead languages. The school farm will be as carefully watched as the school classroom. Precious hours of sunlight will not be wasted indoors or the healthgiving power of light be annulled by over-clothing. Dr. Friend initiated a great work, and Prof. Armstrong has been his staunch supporter, but how many boys' or girls' schools have such enthusiastic medical officers or governors? Though it is an improvement on customary school diets, the Christ's Hospital diet is still far from ideal: sugar is too plentiful; fresh fruit and vegetables too scarce; not all the bread is wholemeal, and more milk and potatoes might with advantage be included. The progress of experiments with improved diets is hampered in schools, and may be invalidated by the unintelligent opposition of the school teaching and domestic staff, and by lack of co-operation from the boys and girls, who resent food changes, and protest if their expenditure on the 'tuck shop' is curtailed. In spite of these obstacles, we hope the time is near when schools will ensure health not by fighting disease with an array of clinical thermometers and antiseptics, but, by means of proper food and sunlight, building sound bodies resistant to infection.

\section{An Experiment in Political Education}

The 'educated electorate' dreamed of by the liberal statesmen of two generations ago is still to seek ; the great mass of voters to-day are probably no better qualified than their ancestors of Gladstone's day to form independent judgments of the merits of rival candidates for election to Parliament. A similar deficiency stultifies democratic government on the other side of the Atlantic. The problem how to help the masses to achieve that critical thinking postulated by democratic theory was discussed in a stirring address delivered on July 26 at the University of Minnesota by Dr. J. W. Studebaker, United States Commissioner of Education. Attention was directed in the address to a remarkable experiment now in operation in Des Moines, Iowa, where the local education authority has inaugurated a public forum for adults. Its objectives are, (1) exchange of information and points of view, (2) development of tolerance and open-mindedness and (3) development of critical intelligence. It is recognised that the leader of such a forum must be a man of eminence in the academic world, with both the theoretical and practical know. ledge of current affairs which would command respect and, above all, "that serene detachment which alone can guarantee clarity of judgment". The basic conception of the forum is educational with emphasis upon critical thinking as opposed to the emotional appeal and obscurantism of the demagogue. Such forums, Mr. Studebaker thinks, ought to be found in every city and village throughout America; and he forecasts support by the Federal Government for schemes for establishing them. University extension discussion classes in Great Britain were started with similar aims, but failed to attract as participants more than a minute proportion of the electorate. It will be interesting to see whether Mr. Studebaker's suggestions fructify.

\section{Origins of Some Mechanical Inventions}

For his presidential address to the Newcomen Society delivered on October 16, Mr. C. F. Dendy Marshall took the subjeet of "The Germs and 